$2018,19(4)$, pp. 963 - 975, DOI : 10.18038/aubtda.430622

\title{
VOLTAMMETRIC DETERMINATION OF ESTRADIOL IN MILK AND PHARMACEUTICALS BASED ON FUMED-SILICA MODIFIED CARBON PASTE ELECTRODE
}

\author{
Ali ÖZCAN ${ }^{1, *}$, Duygu TOPÇUOĞULLARI ${ }^{1}$, Ayça ATILIR ÖZCAN ${ }^{1}$
}

${ }^{1}$ Department of Chemistry, Faculty of Science, Eskişehir Technical University, Eskişehir, Turkey

\begin{abstract}
In this study, modification of carbon paste electrode (CPE) with a nano-structured substance, fumed silica (FS), was investigated to develop a voltammetric method for the determination of an endocrine disrupting chemical, estradiol (EST). FS prominently increased the voltammetric response of CPE towards EST. The parameters that affect the volmametric performance of modified CPE were examined to find the optimal conditions. Modified electrode showed a linear response towards EST between the concentration values of $0.1 \mu \mathrm{M}$ and $15.0 \mu \mathrm{M}$ EST. Limit of detection value for the method developed was calculated as $0.023 \mu \mathrm{M}$. Production reproducibility of the modified electrode was obtained as $3.6 \%$. The voltammetric behavior of EST was also examined in the presence of different substances to evaluate their interference effects. The modified electrode successfully discriminated the oxidation potential of EST in the presence of different substances. The determination of EST was tested in milk and pharmaceutical samples to evaluate the analytical performance of the method. The recovery analysis of EST in milk samples showed that the modified electrode can be used safely in these samples. The modified electrode also achieved the determination of EST in pharmaceutical samples.
\end{abstract}

Keywords: Estradiol, Carbon paste electrode, Voltammetry, Fumed silica

\section{INTRODUCTION}

Endocrine disrupting chemicals (EDCs) can affect the body's endocrine system and produce negative developmental, reproductive and neurological effects on mammals [1,2]. EDCs can alter the functioning of the endocrine system even at very low concentrations, cause different diseases such as breast and prostate cancer, diabetes and obesity $[1,2]$. Estradiol (EST), which is also known as $17 \beta$-estradiol, is a natural oestrogen [3] and also it is an EDC [4]. On the contrary to its negative effects on mammals, EST is widely used in veterinary medicine to heal and to prevent animal infections and also used illegally to fatten animals because of its anabolic effects [5, 6]. As a result of its heavy use in animals, the entrance of EST into food chain is unavoidable. For this reason, it is very important to develop a sensitive, selective and rapid method for the determination of EST.

In recent years, numerous classical analytical methods have been examined for the determination of EST. These methods are high performance liquid chromatography (HPLC) [7, 8], liquid chromatography-mass spectrometry (LC-MS) [9], gas chromatography [10] and immunoassay techniques [11-13]. On the other hand, these methods have several disadvantages since they require use of complicated extraction steps, expensive instruments and long analysis time. Immunoassay techniques can provide high sensitivity for the detection of EST. However, instability of biomolecules in complicated matrixes and the difficulties encountered working with biomolecules restrict the application of these methods [14]. Electrochemical methods with the properties of simple application, fast analysis time and use of inexpensive equipment overcome the certain drawbacks of classical analytical methods. Determination of EST with electroanalytical methods is possible due to the presence of electroactive phenol group in the molecule. In this frame, different studies were performed to prepare different modified electrodes for the determination of EST. Dharuman et al. (2013) prepared an electrode based

*Corresponding Author: aozcan3@anadolu.edu.tr

Received: 04.06.2018 Accepted: 17.12.2018 
on the modification of indium tin oxide with reduced graphene-gold nano-composite [15]. In a different study, a modified electrode was prepared by using a nano-composite including Pt-nano-clusters and multi-walled carbon nanotubes [16]. Moraes et al. (2015) have used reduced graphene oxide and a metal complex porphyrin to prepare a modified electrode [2]. In our previous study, we have prepared a nanocomposite composed of cysteamine self-assembled gold nanoparticle modified fumed silica decorated graphene nanoribbon [17]. Moreover, different electrochemical sensors were also prepared with a polymeric film bearing poly $\{1-$ butyl-3-[3-(N-pyrrole)propyl]imidazole dodecyl sulfonate $\}$ [18], molecule imprinted polymer (MIP) based membranes [3,14,19-21], a DNA aptamer [22] and a nanocomposite containing reduced graphene oxide and rhodium nanoparticles [23].

Carbon paste electrodes (CPEs) are preferred to electrochemical applications compared to other electrodes (glassy carbon, pencil graphite etc.) due to their low background current, wide potential range, quick surfacing and low cost. The significant advantage of CPEs over other electrodes is that they allow the preparation of quickly and easily modified electrodes by adding different substances [24]. Therefore, different materials were used to prepare modified CPEs. In this manner, serpentinite [25], gold nanoparticles [26] and carrageenan hydrogel [27] have been used lately as a modifier.

Fumed-silica (FS) is a nano-sized and synthetic silicone oxide product. It is fabricated via hightemperature flame hydrolysis technique, which involves the conversion of silicon tetra chloride $\left(\mathrm{SiCl}_{4}\right)$ to gas phase using an oxy hydrogen flame. In the gas phase, $\mathrm{SiCl}_{4}$ reacts with water to form silica $\left(\mathrm{SiO}_{2}\right)$ and hydrochloric acid [28]. The surface of FS is covered with highly reactive silanol groups which are available for chemical reactions. Due to its high surface area and non-porous structure, FS has started to be used in cosmetics, paint and coating industries in recent years [29]. FS was also used in electrochemical studies. For example, Kaushik et al. (2009) have prepared a nano-composite using FS and chitosan to determine ochratoxin-A [30]. In our previous studies, we have used FS as a support material for the preparation of different catalysts, which were used in the preparation of modified electrodes $[17,29]$. These studies revealed that FS was a very promising modifier to prepare modified electrodes.

In this study, a simple and very efficient modified CPE was prepared to determine EST in food and pharmaceutical samples. FS was used as a modifier and it increased tremendously the voltammetric response of CPE towards EST. A voltammetric method was developed by optimizing experimental variables such as the percentage of FS, pH and accumulation time. Analytical performance of the method developed was very satisfactory since it has improved analytical parameters such as wide linear range and low detection limit. The effects of some possible interfering substance on the voltammetric behaviour of EST were examined. Finally, determination of EST in milk and pharmaceutical samples was tested. The results showed that FS modified CPE was very efficient in the fast and cheap determination of EST.

\section{MATERIALS AND METHODS}

\subsection{Reagents}

17ß-estradiol (99\%), fumed silica (powder, $14 \mathrm{~nm}$ ), sodium carbonate (anhydrous, 99.5\%), potassium ferricyanide (99\%) and hexamine ruthenium (III) chloride (98\%) were purchased from Sigma-Aldrich. Aqueous solutions were prepared with ultrapure water (Sartorius, Germany). Stock solutions of EST were prepared by using a mixture of acetonitrile; ultra-pure water $(1: 1, \mathrm{v} / \mathrm{v})$ and stored at $+4^{\circ} \mathrm{C}$. Phosphate buffered solutions (PBS) were prepared from $0.1 \mathrm{M} \mathrm{KH}_{2} \mathrm{PO}_{4}(99 \%$, Fluka) solutions. Milk samples was purchased from a local market. Estrofem and Trisequens (Nove Nordisk Sağlık Ürünleri Tic. Ltd. Şti., İstanbul, Turkey) was purchased from a local pharmacy. 


\subsection{Instruments}

Electrochemical measurements were performed with a conventional three-electrode electrochemical cell. CPE and FS modified CPE were used as working electrodes. A home-made Pt-wire electrode and a saturated calomel electrode (SCE, Gammry Instruments, USA) were employed as an auxiliary and reference electrode, respectively. Differential pulse voltammetry (DPV) measurements were performed with an AUTOLAB PGSTAT204 (Netherlands) model potentiostat. Electrochemical impedance spectroscopy (EIS) measurements were performed with a CHI 660D Electrochemical Workstation equipped CHI model 680 Amp Booster (Shanghai Chenhua Co., China).

\subsection{Preparation of Nitric Acid Treated FS (NT-FS)}

Preparation of NT-FS was carried out as previously described in the literature [7]. Briefly, $50 \mathrm{mg}$ FS was added into $4.0 \mathrm{M} \mathrm{HNO}_{3}$ aqueous solution and magnetically stirred for 4 hours. After that, the solid phase was filtered and washed with copies of ultra-pure water. Finally, the solid phase was transferred into a vacuum oven and dried at $65{ }^{\circ} \mathrm{C}$ under vacuum (600 mbar).

\subsection{Preparation of Modified Electrodes}

To prepare CPE, firstly, graphite powder and paraffin oil were mixed in a mass ratio of 70:30 and mixed up to obtain a homogenized paste. After that, the homogenized mixture was packed into a glass electrode holder (internal diameter: $3.0 \mathrm{~mm}$. Length: $13 \mathrm{~cm}$ ) and polished to obtain a smooth surface. The electrical contact was obtained with a copper wire. The modified CPE was fabricated in the same way by adding different amounts of NT-FS (5 - $12.5 \mathrm{wt} \%$ respect to CPE) into the paste structure. The electrodes were denoted as CPE(5NT-FS), CPE(7.5NT-FS), CPE(10NT-FS) and CPE(12.5NT-FS) according to their NT-FS content. A weighing paper was used for smoothing the surface of the electrodes. When the electrodes are not used, they are kept at room temperature.

\subsection{Preparation of Real Samples}

Milk and pharmaceutical samples were examined for the determination of EST. Milk samples were obtained from a local market. Initially, $3.0 \mathrm{~mL}$ milk sample was mixed with $6.0 \mathrm{~mL}$ of acetonitrile and $150 \mu \mathrm{L}$ acetic acid. Acetic acid was used to precipitate proteins found in milk sample. After that, the mixture was vortexed for $2 \mathrm{~min}$ and waited in a dark place for $15 \mathrm{~min}$. Next, the mixture was centrifuged $5000 \mathrm{rpm}$ for $15 \mathrm{~min}$. The resulting liquid phase was diluted to $10 \mathrm{~mL}$ with ultra-pure water.

The pharmaceutical samples were prepared as follows. Two different drugs containing EST were used in the studies. Firstly, ten tablets of each pharmaceutical were grounded and a known amount was weighed. Second, the sample was treated with $50 \mathrm{~mL}$ acetonitrile and the mixture was filtered. After that, final volume was diluted to $100 \mathrm{~mL}$ with ultra-pure water. Standard addition method was used to determine the amount of EST.

\subsection{Voltammetric Measurements}

Voltammetric measurements were performed in an electrochemical cell filled with $10 \mathrm{~mL}$ of $0.1 \mathrm{M}$ phosphate buffered solution for the detection of EST. Differential pulse voltammograms were recorded in the potential values between $+0.2 \mathrm{~V}$ and $+0.8 \mathrm{~V}$. The pulse amplitude and scan rate were selected as $50 \mathrm{mV}$ and $10 \mathrm{mV} \mathrm{s}^{-1}$, respectively. The surface of the modified electrode was renewed at every measurement and electrode surface was polished with a weighing paper. 


\section{RESULTS AND DISCUSSIONS}

\subsection{Evaluation of Voltammetric Performance of the Modified Electrode}

Voltammetric performances of CPE and CPE(12.5NT-FS) were examined via adsorptive differential pulse voltammetry measurements in phosphate buffered solution containing $5.0 \mu \mathrm{M}$ EST (Fig. 1). A well-defined peak indicating the oxidation of EST was observed at $+0.553 \mathrm{~V}$ with CPE. This peak slightly shifted to the potential value of $+0.532 \mathrm{~V}$ in the case of CPE(12.5NT-FS). The oxidation peak current value of EST increased prominently when the CPE(12.5NT-FS) was used instead of CPE. This result reveals that the presence of $12.5 \%$ NT-FS in CPE structure increased the sensitivity of CPE. This may arise from the molecular interaction between silanol (Si-OH) groups found on NT-FS surface and EST. A voltammetric method was developed by using CPE(12.5NT-FS) as a working electrode.

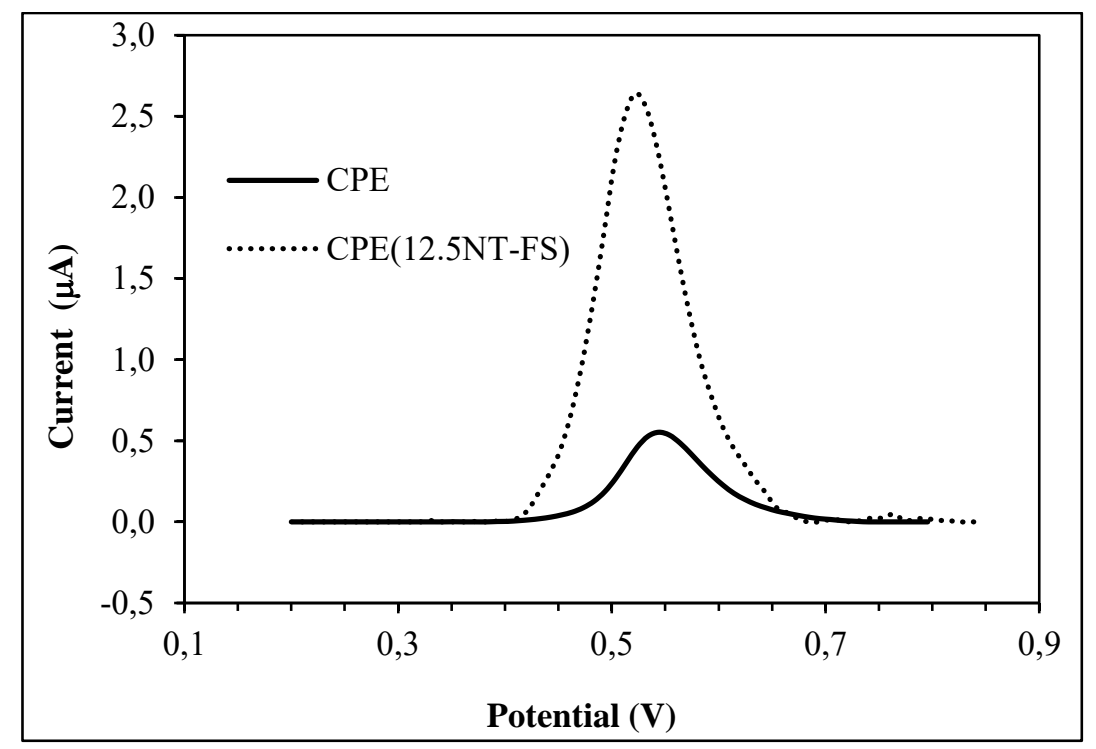

Figure 1. Baseline-corrected differential pulse voltammograms of CPE and CPE(12.5NT-FS) obtained in $0.1 \mathrm{M}$ phosphate buffered solution ( $\mathrm{pH} 6.0$ ) containing $5.0 \mu \mathrm{M}$ EST. Accumulation time: $60 \mathrm{~s}$, stirring rate: $250 \mathrm{rpm}$.

\subsection{Characterization of the Modified Electrode}

Cyclic voltammetry $(\mathrm{CV})$ measurements were performed in $\mathrm{KCl}$ solution containing the negativelycharged redox couple $\left(\mathrm{Fe}(\mathrm{CN})_{6}{ }^{4-3-}\right)$ and positively-charged redox probe $\left(\mathrm{Ru}\left(\mathrm{NH}_{3}\right)_{6}{ }^{3+}\right)$ for the electrochemical characterization of CPE(12.5NT-FS) (Fig. 2). Cyclic voltammograms of $5.0 \mathrm{mM}$ $\mathrm{Fe}(\mathrm{CN})_{6}^{3-4-}$ obtained with bare CPE and CPE(12.5NT-FS) are shown in Figure 2a. A well-defined oxidation peak was observed at $+0.304 \mathrm{~V}$ with bare $\mathrm{CPE}$, which belongs to the oxidation of $\mathrm{Fe}(\mathrm{CN})_{6}{ }^{4-}$. This peak was observed at the potential value of $+0.258 \mathrm{~V}$ for CPE(12.5NT-FS). As seen, a prominent shift $(46 \mathrm{mV})$ was observed with $\mathrm{CPE}(12.5 \mathrm{NT}-\mathrm{FS})$ in the oxidation potential of $\mathrm{Fe}(\mathrm{CN})_{6}{ }^{4-}$. In the reverse scans, the reduction of $\mathrm{Fe}(\mathrm{CN})_{6}{ }^{3-}$ was observed at the potential values of $+0.102 \mathrm{~V}$ and $+0.114 \mathrm{~V}$ for CPE and CPE(12.5NT-FS), respectively. The peak separation values, $\Delta \mathrm{E}_{\mathrm{p}}\left(\mathrm{E}_{\mathrm{pa}}-\mathrm{E}_{\mathrm{pc}}\right)$, were calculated as +0.202 and $+0.144 \mathrm{~V}$ for CPE and CPE(12.5NT-FS), respectively. The decrease in the peak separation values in the presence of the modified electrode and the increase in the peak currents indicate that the presence of NT-FS as a modifier increases the electron transfer rate, which contributes to the electrochemical performance at the electrode surface. 
Measurements were also performed with a positively-charged redox probe $\left(\mathrm{Ru}\left(\mathrm{NH}_{3}\right)_{6}{ }^{3+}\right)$ (Fig. $\left.2 \mathrm{~b}\right)$. A prominent improvement in the electrochemical behaviour of $\mathrm{Ru}\left(\mathrm{NH}_{3}\right)_{6}{ }^{3+}$ was observed with CPE(12.5NT-FS) compared to bare CPE. These results verify that the electron transfer rate of CPE increased prominently in the presence of NT-FS as a modifier.

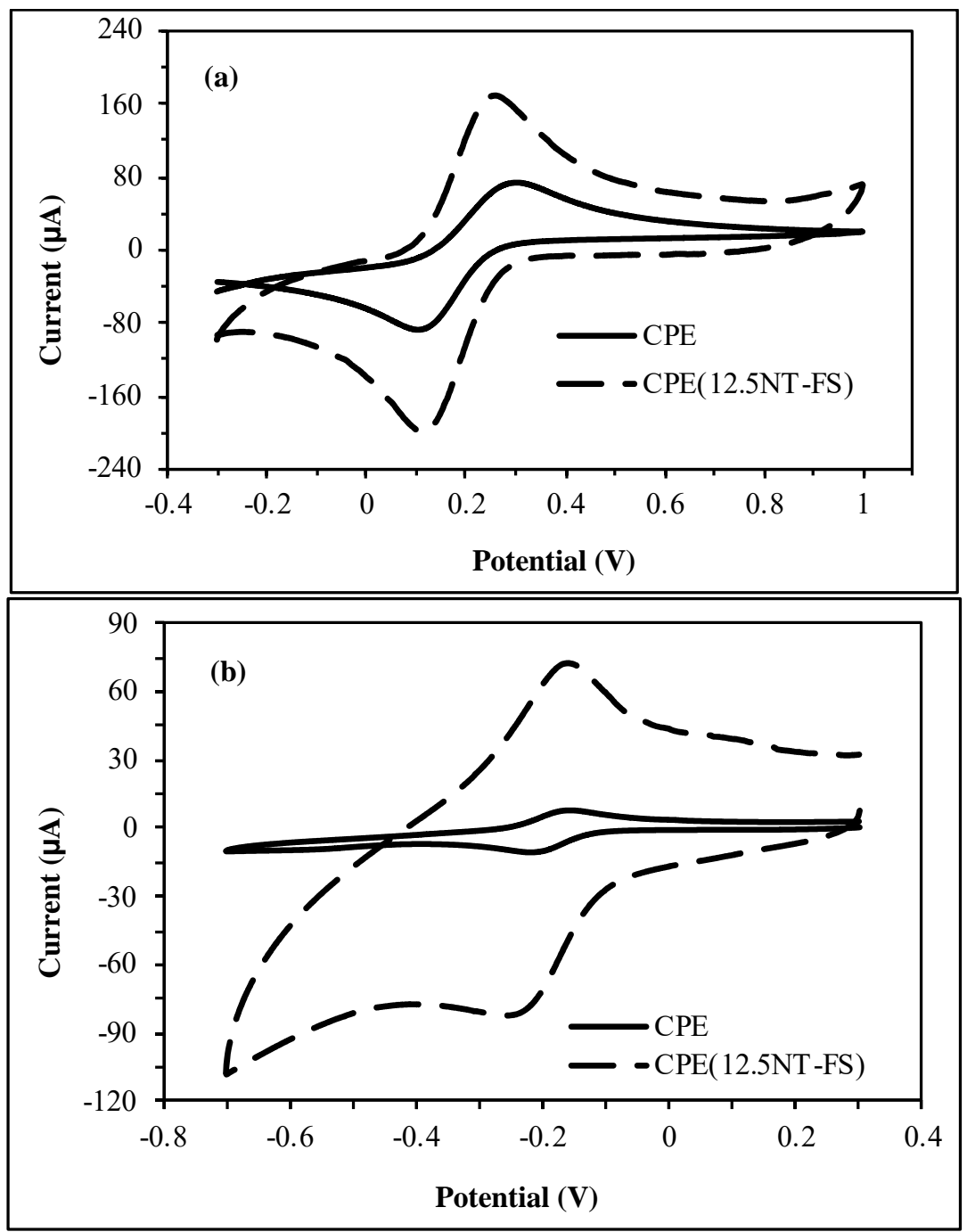

Figure 2. Cyclic voltammograms of $\mathrm{CPE}$ and $\mathrm{CPE}(12.5 \mathrm{NT}-\mathrm{FS})$ obtained in $0.1 \mathrm{M} \mathrm{KCl}$ solutions containing 5.0 $\mathrm{mM} \mathrm{Fe}(\mathrm{CN})_{6}^{4-3-}$ (a) and $1.0 \mathrm{mM} \mathrm{Ru}\left(\mathrm{NH}_{3}\right)^{3+}$ (b). Scan rate: $50 \mathrm{mV} \mathrm{s}^{-1}$.

\subsection{Electrochemical Behaviour of EST at Modified Electrode}

Cyclic voltammetry measurements were performed with CPE(12.5NT-FS) in $0.1 \mathrm{M} \mathrm{PBS}(\mathrm{pH}$ 6) to determine electrochemical behaviour of EST. There was no meaningful electroactivity in the studied potential range in the absence of EST (Fig. 3a). An oxidation peak was appeared at $+0.595 \mathrm{~V}$ after addition of $50.0 \mu \mathrm{M}$ EST into the measurement solution (Fig. 3b). No reduction peak was seen in the reverse scan. This result indicates that the electrochemical oxidation of EST on CPE(12.5NT-FS) is not reversible. 
Özcan et al. / Eskişehir Technical Univ. J. of Sci. and Tech. A-Appl. Sci. and Eng. 19 (4) - 2018

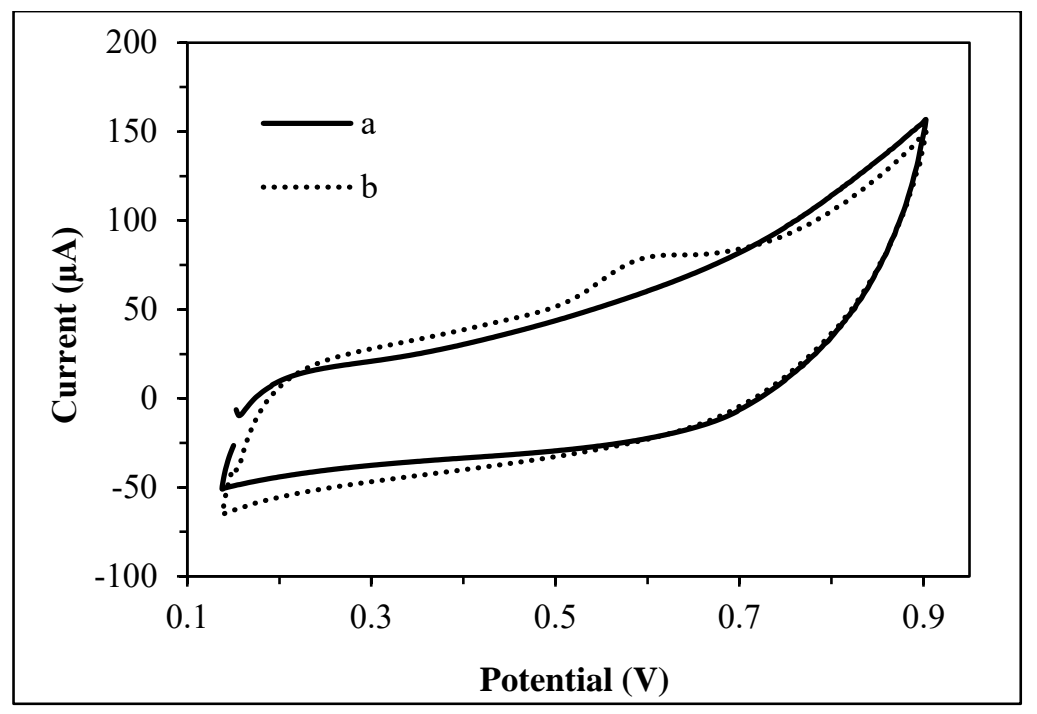

Figure 3. Cyclic voltammograms of CPE(12.5NT-FS) obtained in $0.1 \mathrm{M} \mathrm{PBS}(\mathrm{pH} 6.0$ ) in the absence (a) and presence of $50.0 \mu \mathrm{M}$ EST (b). Accumulation time: $60 \mathrm{~s}$, stirring rate: $250 \mathrm{rpm}$.

\subsection{The Effects of NT-FS Amount on the Voltammetric Response of the Electrode}

A series of modified electrodes were prepared by mixing graphite powder with different amounts of NT-FS $(5 \%, 7.5 \%, 10 \%$ and $12.5 \%)$ to evaluate the effects of NT-FS amount on the voltammetric response of the modified electrode. The oxidation peak current values of $5.0 \mu \mathrm{M}$ EST are shown in Figure 4. As seen, the oxidation peak current of EST gradually increased by the increase of NT-FS amount in paste structure. The voltammetric response of bare CPE towards EST increased 6 times in the presence of $12.5 \%$ NT-FS. After this value, further increase in NT-FS content led to paste preparation problems. Therefore, this value was selected as the optimal value.

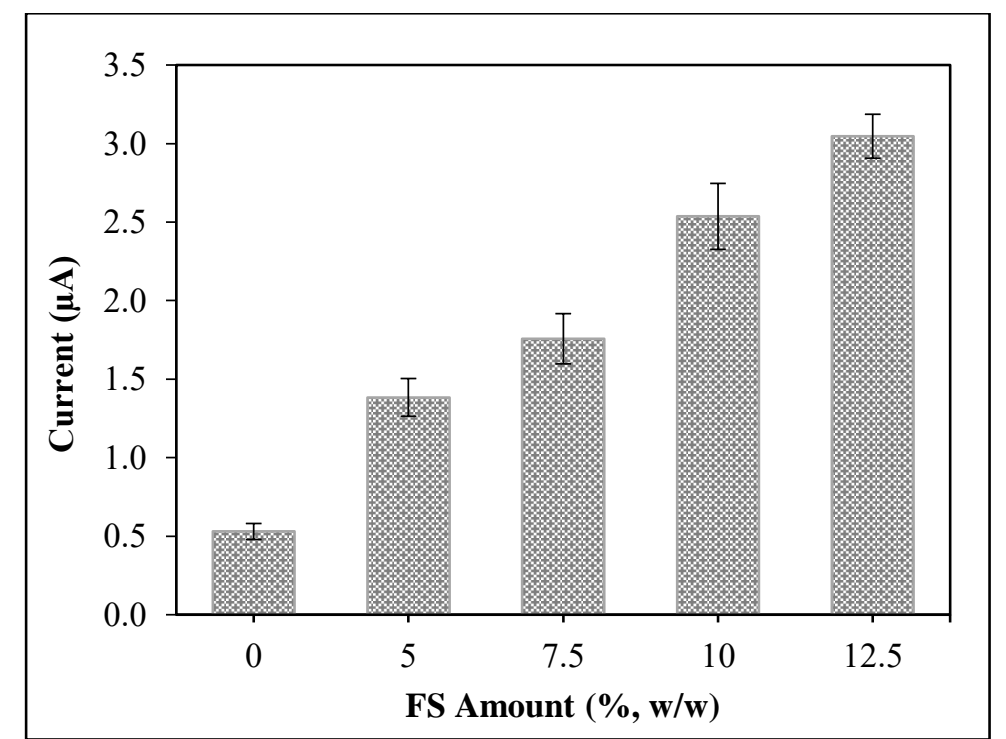

Figure 4. The oxidation peak current values of 5.0 $\mu \mathrm{M}$ EST obtained in $0.1 \mathrm{M}$ PBS (pH 6.0) with modified CPEs containing different amounts of NT-FS. Accumulation time: $60 \mathrm{~s}$, stirring rate: $250 \mathrm{rpm}$. 


\subsection{Optimization of Measurement Conditions}

Differential pulse voltammetry measurements at different $\mathrm{pH}$ values were conducted to evaluate the effect of $\mathrm{pH}$ on the voltammetric response of the CPE(12.5NT-FS). The differential pulse voltammograms, which were obtained in PBS having different $\mathrm{pH}$ values, were given in Figure 5. As can be seen from Figure 5, the oxidation of EST on CPE(12.5NT-FS) took place at all the $\mathrm{pH}$ values studied. The intensity of the peak started to increase by the increase of $\mathrm{pH}$. It reached to its highest value at $\mathrm{pH}$ 6.0. After this value, further increase of $\mathrm{pH}$ led to a dramatic decrease in the intensity of the oxidation peak. Therefore, optimal value was selected as 6.0. A linear relationship was observed between the oxidation potential of EST and $\mathrm{pH}$, having an equation of $\mathrm{E}(\mathrm{V})=-0.0471 \mathrm{pH}+0.824\left(\mathrm{R}^{2}\right.$ : $0.9868)$. The slope $(-0.0471)$ of this line is very close to the theoretical value of -0.0592 , which showing the presence of same number of protons and electrons in the redox reaction of EST.

Another parameter that was examined was the accumulation time. To investigate this parameter, CPE(12.5NT-FS) was immersed into EST solution, waited different time periods and differential pulse voltammetry measurements were performed (Fig. 6). The oxidation peak current of EST gradually increased by the increase of accumulation time. This increase continued up to $240 \mathrm{~s}$. After this time, a slight decrease in the oxidation peak current was observed. Therefore, the optimum accumulation time was chosen as $240 \mathrm{~s}$ and used in the subsequent experiments.

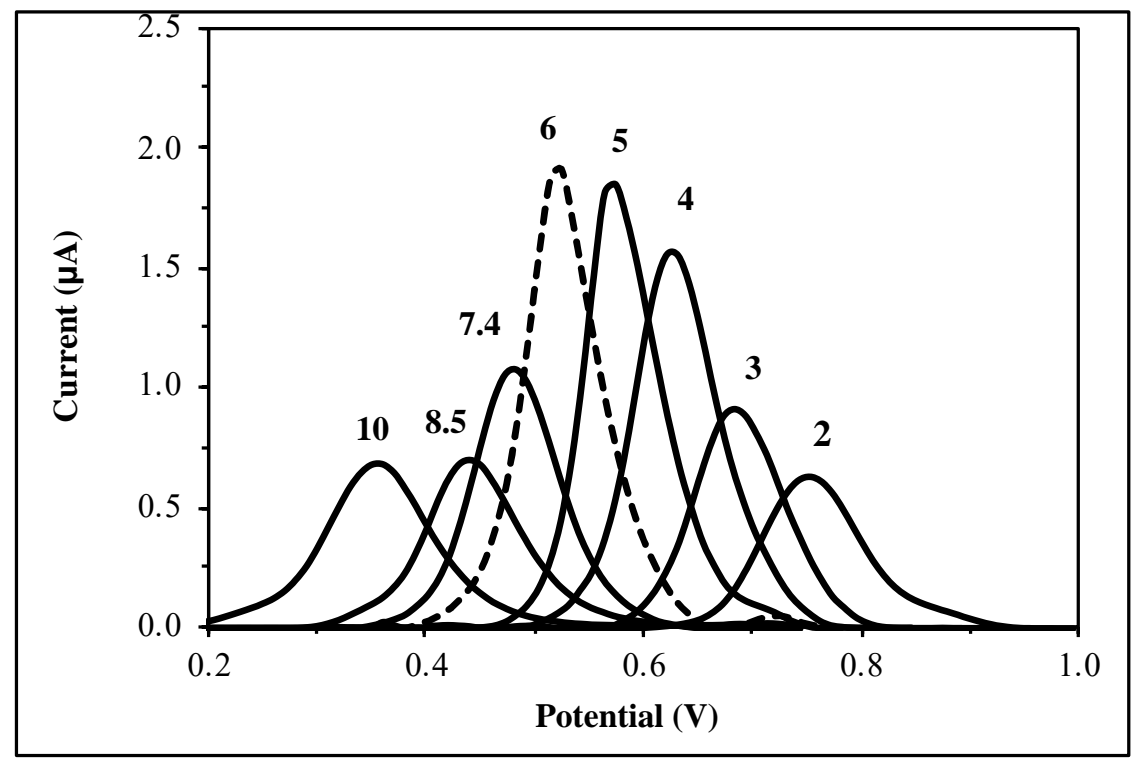

Figure 5. Baseline-corrected differential pulse voltammograms of 5.0 $\mu \mathrm{M}$ EST obtained with CPE(12.5NT-FS) in PBS having different $\mathrm{pH}$ values. Accumulation time: $60 \mathrm{~s}$, stirring rate: $250 \mathrm{rpm}$ 


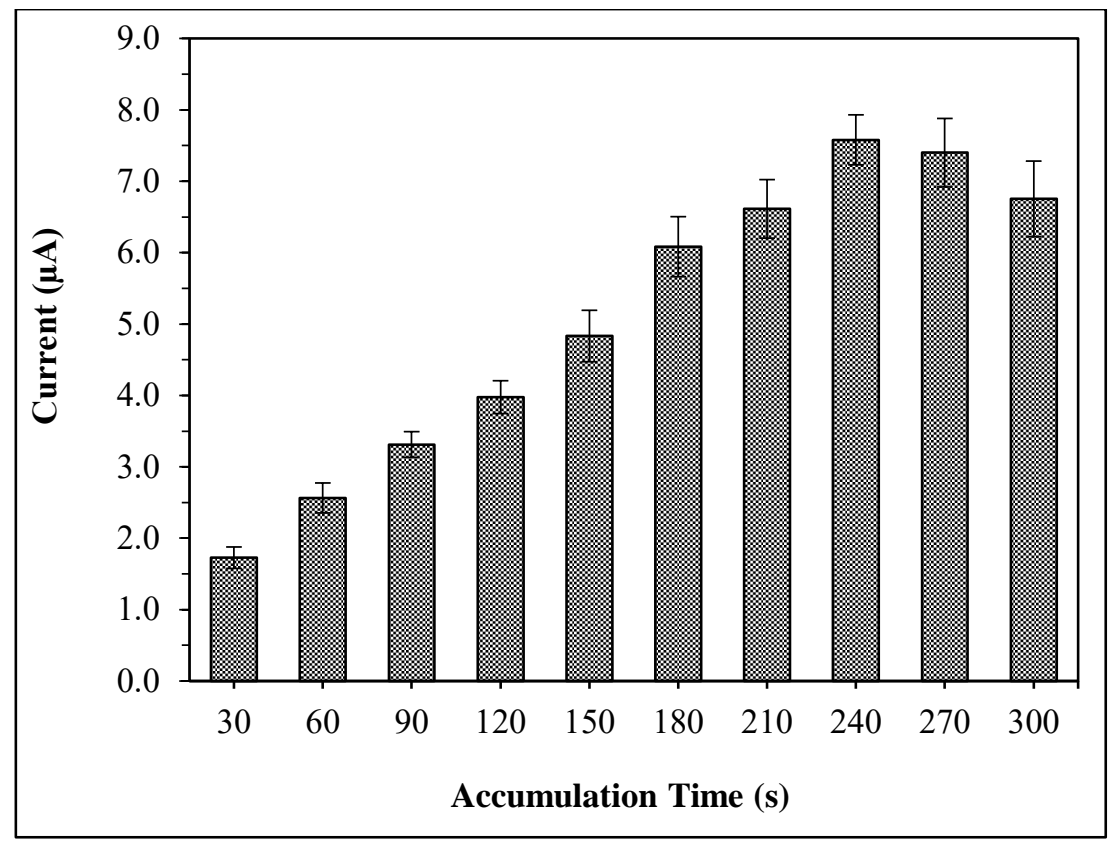

Figure 6. The effects of accumulation time on the oxidation peak currents of 5.0 $\mu$ M EST in 0.1 M PBS (pH: 6.0).

\subsection{Evaluation of the Effects of Possible Interfering Substances}

The effects of different species that might be found in real samples on the voltammetric response of CPE(12.5NT-FS) were investigated to determine their interfering effects. No meaningful change was observed in the voltammetric response of $5.0 \mu \mathrm{M}$ EST in the presence of excess amounts of ascorbic acid $(1000 \mu \mathrm{M})$, uric acid $(100 \mu \mathrm{M})$, potassium chloride $(2000 \mu \mathrm{M})$, calcium chloride $(2000 \mu \mathrm{M})$, glucose $(2000 \mu \mathrm{M})$, urea $(2000 \mu \mathrm{M})$, citric acid $(2000 \mu \mathrm{M})$ and o-nitrophenol $(25 \mu \mathrm{M})$. These results indicate that CPE(12.5NT-FS) allows the selective determination of EST in the presence of different substances.

\subsection{Determination of Analytical Parameters}

To determine linear range and detection limit of the proposed method, DPV measurements were performed with CPE(12.5NT-FS) at optimized conditions and peak currents were recorded. The oxidation peak currents of EST increased linearly between the concentration values of $0.1 \mu \mathrm{M}$ and 15.0 $\mu \mathrm{M}$ (Fig. 7a). The calibration plot displayed a good linearity and a wide working range with a linear equation of $\mathrm{I}(\mu \mathrm{A})=1.26 \mathrm{C}_{\mathrm{EST}}(\mu \mathrm{M})+0.33\left(\mathrm{R}^{2}=0.996\right)$. The limit of detection $(\mathrm{LOD})$ value and limit of quantification (LOQ) were calculated as $0.023 \mu \mathrm{M}$ and $0.077 \mu \mathrm{M}$, respectively, taking the signal/noise $(\mathrm{S} / \mathrm{N})$ ratio 3 and 10 , respectively. It is important to note that the measurements were repeated with bare CPE at the same conditions, but the oxidation peak currents of EST obtained with bare CPE did not show linearity in the studied concentration range (Fig. 7b). These results show that NT-FS has a prominent effect on the performance of CPE.

The fabrication reproducibility of CPE(12.5NT-FS) was evaluated by measuring $5.0 \mu \mathrm{M}$ EST with ten different fresh electrodes. Relative standard deviation of the measurements was calculated as $3.6 \%$, indicating high production reproducibility of CPE(12.5NT-FS). 


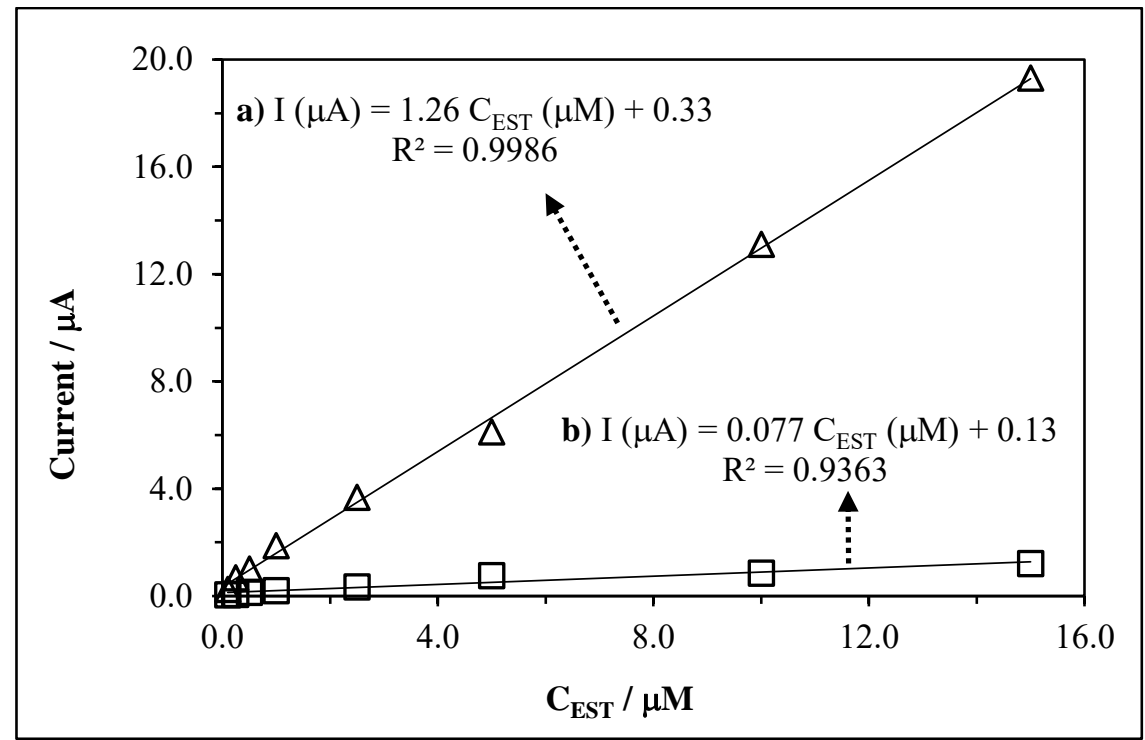

Figure 7. The calibration curves for EST obtained in $0.1 \mathrm{M}$ PBS (pH: 6.0) by CPE(12.5NT-FS) (a) and CPE (b) electrodes. Accumulation time: $240 \mathrm{~s}$, stirring rate: $250 \mathrm{rpm}$.

\subsection{Investigation of the Performance of CPE(12.5NT-FS) in Real Samples}

The performance of CPE(12.5NT-FS) in real samples is very important from analytical chemistry. Therefore, determination of EST with CPE(12.5NT-FS) was examined in milk and pharmaceutical samples. Firstly, milk samples were prepared and measurements were performed. Differential pulse voltammogram of fifty-times diluted milk sample was given in Figure 8. As can be seen from the figure, there was no noticeable peak at the oxidation potential value of EST, indicating that there was no EST in the original milk sample. To evaluate the performance of CPE(12.5NT-FS), EST-spiked milk samples were prepared and measurements were repeated (Fig. 9). A well-defined oxidation peak was observed at $+0.57 \mathrm{~V}$, which corresponds to the oxidation of EST (Fig. 9, dotted line). The intensity of this peak gradually increased with the increase of EST concentration in the measurement medium (Fig. 9, straight lines). Another oxidation peak was also observed at $+0.36 \mathrm{~V}$, which may correspond to oxidation of an electroactive substance that found in the milk sample. The presence of this peak did not prevent the selective determination of EST. These results show that CPE(12.5NT-FS) can be used in the determination of EST in milk samples. The results obtained during the recovery studies were given in Table 1 . The recovery values are in the range of $92.47 \%$ and $100.04 \%$, indicating high recovery of EST.

The applicability of the method was also tested in two different pharmaceutical samples. The EST content of pharmaceutical samples were determined with the proposed method by using standard addition method. The amount of EST found in pharmaceutical samples were determined as $2.051 \mathrm{mg}$ tablet $^{-1}$ and $2.087 \mathrm{mg}^{-1 a b l e t}{ }^{-1}$. The EST content of the pharmaceutical samples studied here was indicated as $2.00 \mathrm{mg}^{\text {tablet }}{ }^{-1}$ by the producer companies. As can be seen, the values obtained with our proposed method were comparable with that of the reported values. These results revealed that the proposed method can also be used in the determination of EST in pharmaceutical samples. 
Özcan et al. / Eskişehir Technical Univ. J. of Sci. and Tech. A-Appl. Sci. and Eng. 19 (4) - 2018

Table 1. Results of recovery analysis of EST in milk samples.

\begin{tabular}{llll}
\hline Sample & Added $(\mu \mathrm{M})$ & Detected $(\mu \mathrm{M})$ & $\%$ Recovery \\
\hline \multirow{2}{*}{ MS-A } & 0.0 & Not detected & --- \\
\cline { 2 - 4 } & 50.0 & 50.02 & 100.04 \\
\hline \multirow{2}{*}{ MS-B } & 0.0 & Not detected & --- \\
\cline { 2 - 4 } & 100 & 92.47 & 92.47 \\
\hline
\end{tabular}

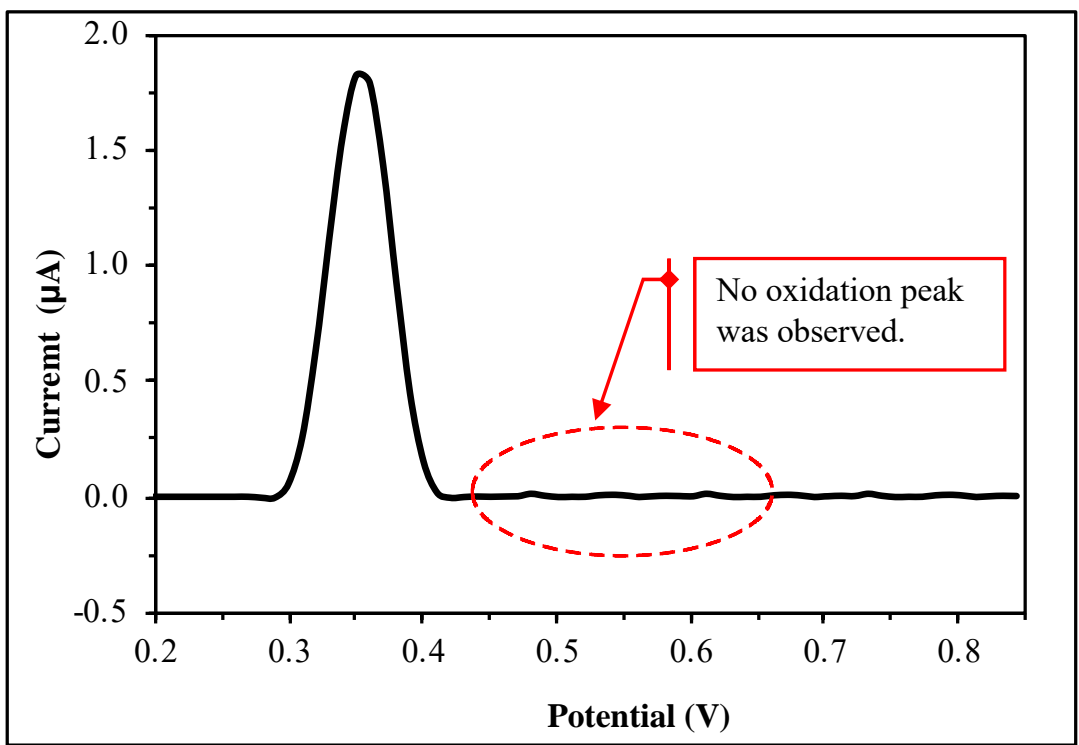

Figure 8. Baseline-corrected DPV of fifty-times diluted milk sample obtained in 0.1 M PBS (pH: 6) with CPE(12.5NT-FS). Accumulation time: $240 \mathrm{~s}$, stirring rate: $250 \mathrm{rpm}$.

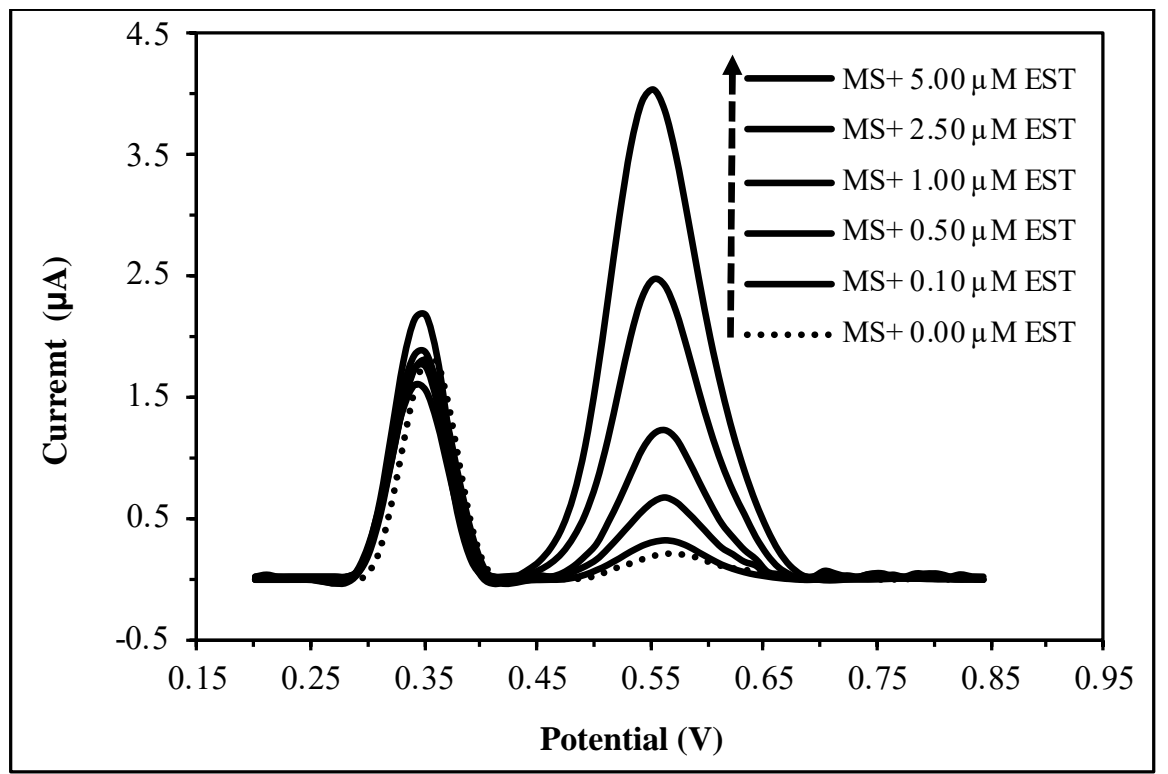

Figure 9. Baseline-corrected DPVs of fifty-times diluted EST-spiked milk sample obtained in 0.1 M PBS (pH: 6) with $\mathrm{CPE}(12.5 \mathrm{NT}-\mathrm{FS})$ in the absence (dotted line) and presence (straight lines) of increasing concentrations of EST. Accumulation time: $240 \mathrm{~s}$, stirring rate: $250 \mathrm{rpm}$. 


\section{CONCLUSIONS}

In this study, a voltammetric method was developed for the determination of EST in milk and pharmaceutical samples. This new method was based on the modification of CPE with FS, which was a nanosized silicon oxide substance. Electrochemical characterization studies revealed that the presence of FS in CPE increased prominently the electron transfer rate of redox species of $\mathrm{Fe}(\mathrm{CN})_{6}^{4-/ 3-}$ and $\mathrm{Ru}\left(\mathrm{NH}_{3}\right)_{6}{ }^{3+}$. The oxidation peak current of EST obtained with CPE(12.5NT-FS) was 6-times higher than that of obtained with CPE. The CPE(12.5NT-FS) has the properties of wide linear range, low detection limit, short analysis time and log-term stability. The determination of EST in milk and pharmaceutical samples successfully achieved with the method proposed here.

\section{REFERENCES}

[1] Ji L, Wang Y, Wu K, Zhang W. Simultaneous determination of environmental estrogens: Diethylstilbestrol and estradiol using Cu-BTC frameworks-sensitized electrode. Talanta 2016; 159: 215-21.

[2] Moraes FC, Rossi B, Donatoni MC, de Oliveira KT, Pereira EC. Sensitive determination of 17 $\beta$ estradiol in river water using a graphene based electrochemical sensor. Anal Chim Acta 2015; 881: $37-43$.

[3] Zhang X, Peng Y, Bai J, Ning B, Sun S, Hong X, et al. A novel electrochemical sensor based on electropolymerized molecularly imprinted polymer and gold nanomaterials amplification for estradiol detection. Sens Actuat B: Chem 2014; 200: 69-75.

[4] Kang JH, Kondo F, Katayama Y. Human exposure to bisphenol A. Toxicology 2006; 226(2-3): 79-89.

[5] Monerris MJ, Arivalo FJ, Fernandez H, Zon MA, Molina PG. Development of a very sensitive electrochemical immunosensor for the determination of $17 \beta$-estradiol in bovine serum samples. Sens Actuat B: Chem 2015; 208: 525-31.

[6] Huang KJ, Liu YJ, Zhang JZ, Cao JT, Liu YM. Aptamer/Au nanoparticles/cobalt sulfide nanosheets biosensor for $17 \beta$-estradiol detection using a guanine-rich complementary DNA sequence for signal amplification. Biosens Bioelectron 2015; 67: 184-91.

[7] Yoon Y, Westerhoff P, Snyder SA, Esparza M. HPLC-fluorescence detection and adsorption of bisphenol A, 17 $\beta$-estradiol, and 17 $\alpha$-ethynyl estradiol on powdered activated carbon. Water Res 2003; 37(14): 3530-7.

[8] Jiang T, Zhao L, Chu B, Feng Q, Yan W, Lin JM. Molecularly imprinted solid-phase extraction for the selective determination of $17 \beta$-estradiol in fishery samples with high performance liquid chromatography. Talanta 2009; 78(2): 442-7.

[9] Joong S, Taye K, Yong S, Dartois V, Nae S, Bae D, et al. Development and validation of LC-ESIMS/MS method for analysis of moxifloxacin and levofloxacin in serum of multidrug-resistant tuberculosis patients: Potential application as therapeutic drug monitoring tool in medical diagnosis. J Chromatogr B Analyt Technol Biomed Life Sci 2016; 1010: 138-43.

[10] Choi MH, Kim KR, Chung BC. Determination of estrone and 17ß-estradiol in human hair by gas chromatography-mass spectrometry. Analyst 2000; 125(4): 711-4. 
[11] Tanaka T, Takeda H, Ueki F, Obata K, Tajima H, Takeyama H, et al. Rapid and sensitive detection of $17 \beta$-estradiol in environmental water using automated immunoassay system with bacterial magnetic particles. J Biotechnol 2004; 108(2): 153-9.

[12] Shanin IA, Thuy NTD, Eremin SA. Determination of levofloxacin (the Levorotatory Stereoisomer of Ofloxacin) in milk by an indirect enzyme-linked immunosorbent assay. Moscow Univ Chem Bull 2014; 69(3): 136-41.

[13] Volpe G, Fares G, Quadri F delli, Draisci R, Ferretti G, Marchiafava C, et al. A disposable immunosensor for detection of $17 \beta$-estradiol in non-extracted bovine serum. Anal Chim Acta 2006; 572(1): 11-6.

[14] Wen T, Xue C, Li Y, Wang Y, Wang R, Hong J, et al. Reduced graphene oxide-platinum nanoparticles composites based imprinting sensor for sensitively electrochemical analysis of $17 \beta-$ estradiol. J Electroanal Chem 2012; 682: 121-7.

[15] Dharuman V, Hahn JH, Jayakumar K, Teng W. Electrochemically reduced graphene-gold nano particle composite on indium tin oxide for label free immuno sensing of estradiol. Electrochim Acta 2013; 114: 590-7.

[16] Lin X, Li Y. A sensitive determination of estrogens with a Pt nano-clusters/multi-walled carbon nanotubes modified glassy carbon electrode. Biosens Bioelectron 2006; 22(2): 253-9.

[17] Özcan A, Topçuoğulları D. Voltammetric determination of 17-B-estradiol by cysteamine selfassembled gold nanoparticle modified fumed silica decorated graphene nanoribbon nanocomposite. Sens Actuat B: Chem 2017; 250: 85-90.

[18] Wang Z, Wang P, Tu X, Wu Y, Zhan G, Li C. A novel electrochemical sensor for estradiol based on nanoporous polymeric film bearing poly\{1-butyl-3-[3-(N-pyrrole)propyl]imidazole dodecyl sulfonate\} moiety. Sens Actuat B: Chem 2014; 193: 190-7.

[19] Yuan L, Zhang J, Zhou P, Chen J, Wang R, Wen T, et al. Electrochemical sensor based on molecularly imprinted membranes at platinum nanoparticles-modified electrode for determination of 17 $\beta$-estradiol. Biosens Bioelectron 2011; 29(1): 29-33.

[20] Li Y, Zhao X, Li P, Huang Y, Wang J, Zhang J. Highly sensitive Fe3O4 nanobeads/graphene-based molecularly imprinted electrochemical sensor for 17ß-estradiol in water. Anal Chim Acta 2015; 884: 106-13.

[21] Florea A, Cristea C, Vocanson F, Səndulescu R, Jaffrezic-Renault N. Electrochemical sensor for the detection of estradiol based on electropolymerized molecularly imprinted polythioaniline film with signal amplification using gold nanoparticles. Electrochem Commun 2015; 59: 36-9.

[22] Kim YS, Jung HS, Matsuura T, Lee HY, Kawai T, Gu MB. Electrochemical detection of 17ßestradiol using DNA aptamer immobilized gold electrode chip. Biosens Bioelectron 2007; 22(11): $2525-31$.

[23] Povedano E, Cincotto FH, Parrado C, Díez P, Sánchez A, Canevari TC, et al. Decoration of reduced graphene oxide with rhodium nanoparticles for the design of a sensitive electrochemical enzyme biosensor for 17 $\beta$-estradiol. Biosens Bioelectron 2017; 89: 343-51. 
[24] Ourari A, Ketfi B, Malha SIR, Amine A. Electrocatalytic reduction of nitrite and bromate and their highly sensitive determination on carbon paste electrode modified with new copper Schiff base complex. J Electroanal Chem 2017; 797(May): 31-6.

[25] Ranđelović MS, Momčilović MZ, Nikolić G, Đordević JS. Electrocatalitic behaviour of serpentinite modified carbon paste electrode. J Electroanal Chem 2017; 801: 338-44.

[26] Saleh TA, AlAqad KMM, Rahim A. Electrochemical sensor for the determination of ketoconazole based on gold nanoparticles modified carbon paste electrode. J Mol Liq 2018; 256: 39-48.

[27] Núñez C, Arancibia V, Triviño JJ. A new strategy for the modification of a carbon paste electrode with carrageenan hydrogel for a sensitive and selective determination of arsenic in natural waters. Talanta 2018; 187: 259-64.

[28] Cochrane H, Lin CS. The Influence of Fumed Silica Properties on the Processing, Curing, and Reinforcement Properties of Silicone Rubber. Rubber Chem and Technol 1993; 66(1): 48-60.

[29] Özcan A, Gürbüz M, Özbal A. Preparation of a double-step modified carbon paste electrode for the voltammetric determination of propham via bulk modification with fumed silica and drop-casting of maghemite-modified fumed silica nanocomposite. Sens Actuat B: Chem 2018; 255: 1517-24.

[30] Kaushik A, Solanki PR, Sood KN, Ahmad S, Malhotra BD. Fumed silica nanoparticles-chitosan nanobiocomposite for ochratoxin-A detection. Electrochem Commun 2009; 11(10): 1919-23. 